\title{
ANALISIS KONTROL OPTIMAL PADA MODEL MATEMATIKA PENYEBARAN PENGGUNA NARKOBA DENGAN FAKTOR EDUKASI
}

\author{
Resmawan'1, M. Eka², Nurwan³ ${ }^{3}$ N. Achmad4 \\ 1,2,3,4 Program Studi Matematika Jurusan Matematika \\ FMIPA Universitas Negeri Gorontalo, JI. Prof. Dr. Ing. B. J. Habibie \\ Kabupaten Bone Bolango 96119, Gorontalo, Indonesia

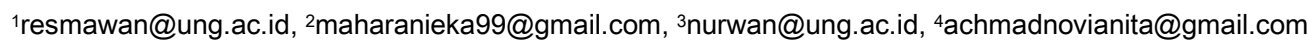

\begin{abstract}
This paper discusses the mathematical model of drug users with education. Optimal control theory was used on this model with education as a control to achieve the goal of minimizing the number of drug users. The optimal control problem was analyzed using Pontryagin's minimum principle and performed numerical simulation by using a 4th-order Runge-Kutta method. Based on the numerical simulation, there was a change in the number in each population which caused the population with education to increase, and control with education resulted in the reduced number of drug users.
\end{abstract}

Keywords : Drug Users, Education, Mathematical Model, Optimal Kontrol

\section{ABSTRAK}

Artikel ini membahas tentang model matematika penyebaran pengguna narkoba dengan faktor edukasi. Teori kontrol optimal diterapkan pada model ini dengan pemberian kontrol berupa edukasi dengan tujuan untuk meminimumkan jumlah pengguna narkoba. Kontrol optimal dianalisis menggunakan Prinsip Minimum Pontryagin dan dilakukan simulasi numerik dengan menggunakan metode Runge-Kutta orde 4. Berdasarkan simulasi diperoleh bahwa terjadi perubahan jumlah di tiap populasi dan mengakibatkan jumlah populasi dengan edukasi bertambah, serta pemberian kontrol dengan edukasi mengakibatkan jumlah pengguna narkoba berkurang.

Kata kunci : : Pengguna Narkoba, Edukasi, Model Matematika, Kontrol Optimal 


\section{PENDAHULUAN}

Dalam Undang-Undang Republik Indonesia Nomor 35 Tahun 2009 Tentang Narkotika ditegaskan bahwa narkotika adalah zat atau obat yang berasal dari tanaman atau bukan tanaman, baik sintetis maupun semisintetis, yang dapat menyebabkan penurunan atau perubahan kesadaran, hilangnya rasa, mengurangi sampai menghilangkan rasa nyeri, dan dapat menimbulkan ketergantungan. Maraknya peredaran narkoba sangat meresahkan masyarakat apalagi di kalangan remaja dan anak muda (Wijayanti, 2016). Berdasarkan informasi Badan Narkotika Nasional (BNN) pada tahun 2019, penyalahgunaan narkotika di kalangan remaja makin meningkat. Penyalahgunaan narkoba tahun 2017 mencapai angka 3,4 juta orang pada rentang usia 10-59 tahun, sedangkan pada tahun 2018 mencapai angka 2,29 juta orang. Salah satu kelompok masyarakat yang rawan terpapar penyalahgunaan narkoba adalah mereka yang berada pada rentang usia 15-35 tahun atau generasi milenial (BNN, 2019).

Salah satu upaya yang dapat dilakukan untuk menemukan solusi dari masalah penyebaran narkoba adalah melalui pendekatan model matematika. Model matematika tentang penyebaran pengguna narkoba pertama kali diperkenalkan oleh White dan Comiskey (2007) yang membagi total populasi manusia menjadi tiga kelas, yaitu kelas individu yang rentan (susceptible) menjadi pengguna narkoba, kelas individu pengguna narkoba tidak dalam masa pengobatan, dan kelas individu pengguna narkoba dalam masa pengobatan. Pada model tersebut dilakukan identifikasi dan analisis sensitivitas bilangan reproduksi dasar $R_{0}$. Selanjutnya Mulone dan Straughan (2009) serta Wang dkk (2011) model tersebut dianalisis titik kesetimbangannya. Selanjutnya Husain dkk (2020) membentuk model matematika penyebaran pengguna narkoba dengan faktor edukasi. Pada model tersebut diperoleh bahwa titik kesetimbangan bebas narkoba stabil pada kondisi $R_{0}<1$ dan titik kesetimbangan endemik stabil pada kondisi $R_{0}>1$.

Pada artikel ini, diperkenalkan model baru penyebaran narkoba dengan memperhatikan adanya populasi yang telah berhenti dari pengguna narkoba $(R)$. Modifikasi selanjutnya dilakukan dengan mempertimbangkan faktor edukasi pada setiap kelas populasi. Analisis lebih lanjut pada model dilakukan dengan menambahkan parameter kontrol. Penerapan kontrol optimal pada model dibutuhkan untuk membantu dalam membuat keputusan tentang pencapaian suatu tujuan dalam situasi biologis yang kompleks (Hota dkk, 2015). Beberapa penelitian yang menerapkan kontrol optimal diantaranya penelitian yang dilakukan oleh Oke dkk (2018) pada model kanker payudara dengan diet katogenik dan obat anti kanker sebagai kontrol dan Engelhart dkk (2011) menggunakan kontrol optimal pada model kanker dengan kemoterapi. Dalam penelitian ini, kontrol optimal digunakan untuk meminimumkan jumlah penyebaran pengguna narkoba. 


\section{METODE PENELITIAN}

Metode yang dilakukan pada penelitian ini adalah studi literatur dengan menelusuri dan mempelajari jurnal dan referensi yang berkaitan dengan model matematika penyebaran pengguna narkoba. Langkah-langkah yang dilakukan adalah sebagai berikut:

1. Menentukan asumsi-asumsi yang akan digunakan untuk membuat skema model matematika penyebaran pengguna narkoba.

2. Membentuk model matematika penyebaran pengguna narkoba yang akan dipelajari berdasarkan asumsi yang diberikan.

3. Menambahkan parameter kontrol pada model yang telah dibentuk.

4. Menentukan persamaan Lagrangian dan Hamilton dari masalah kontrol optimal.

5. Menentukan solusi $u(t)$ untuk mendapatkan kondisi yang optimal.

6. Melakukan simulasi numerik berdasarkan hasil dari analisis kontrol optimal.

7. Menginterpretasikan hasil simulasi dan membuat simpulan dari hasil yang diperoleh.

\section{HASIL DAN PEMBAHASAN}

\subsection{Model Matematika}

Model dimodifikasi dari model dasar White dan Comiskey (2007) dengan beberapa asumsi sebagai berikut:

1. Penambahan kelas populasi yang telah berhenti dari pengguna narkoba, yang dinotasikan sebagai $(R)$.

2. Adanya faktor edukasi pada setiap kelas populasi, menambah variabel model berupa kelas populasi rentan yang diberi edukasi $\left(S_{e}\right)$, kelas populasi pengguna narkoba yang diberi edukasi $\left(U_{e}\right)$, dan kelas populasi berhenti dari pengguna narkoba yang diberi edukasi $\left(R_{e}\right)$.

3. Masih adanya pengguna narkoba yang telah berhenti dari menggunakan narkoba $(R)$ yang berpotensi untuk kembali rentan menjadi pengguna narkoba sehingga menghasilkan model tipe SURS pada populasi tanpa faktor edukasi.

4. Total populasi dituliskan $N=S+U+R+S_{e}+U_{e}+R_{e}$.

Sebagaimana dalam Nebi (2019) edukasi pada kelas populasi rentan pengguna narkoba $\left(S_{e}\right)$ diberikan dengan maksud untuk mencegah mereka jadi pengguna narkoba. Edukasi yang diberikan pada populasi pengguna narkoba $\left(U_{e}\right)$ dimaksudkan untuk memberi pemahaman dan membantu mereka berhenti dari pengguna narkoba. Adapun edukasi yang diberikan pada kelas populasi yang telah berhenti dari pengguna narkoba $\left(R_{e}\right)$ dimaksudkan untuk mencegah mereka kembali menjadi pengguna narkoba. Hal ini sejalan dengan fakta masih adanya pengguna narkoba yang telah berhenti dari menggunakan narkoba $(R)$ yang berpotensi untuk kembali rentan menjadi pengguna narkoba. Berdasarkan asumsi tersebut diperoleh skema model yang ditunjukkan pada Gambar 1. 


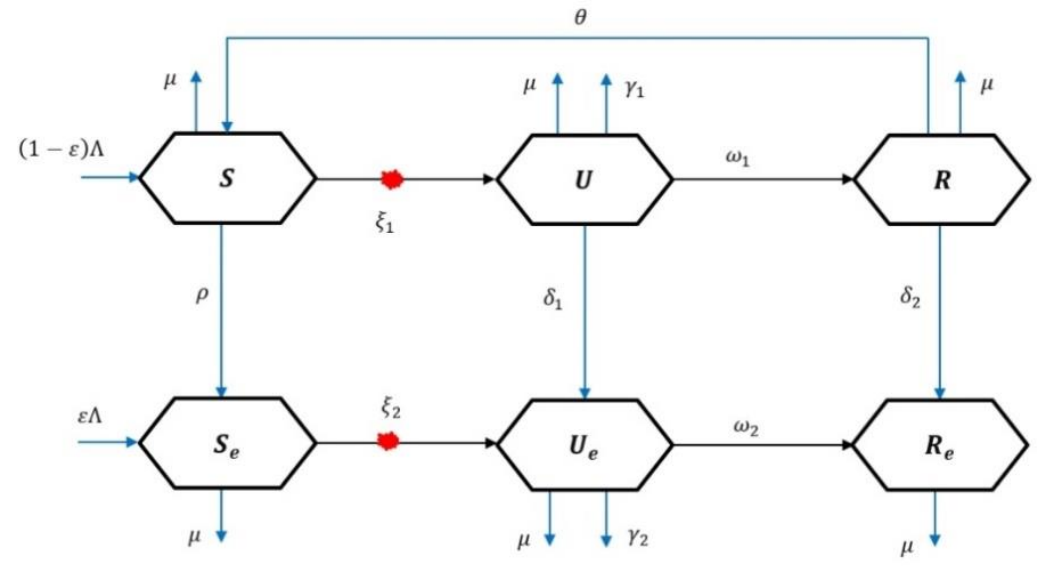

Gambar 1 : Skema Model Penyebaran Pengguna Narkoba Dengan Faktor Edukasi

Berdasarkan skema pada Gambar 1, diperoleh model matematika dalam bentuk sistem persamaan diferensial.

$$
\begin{aligned}
& \frac{d S}{d t}=(1-\varepsilon) \Lambda+\theta R-\xi_{1} S-(\rho+\mu) S \\
& \frac{d S_{e}}{d t}=\varepsilon \Lambda+\rho S-\xi_{2} S_{e}-\mu S_{e} \\
& \frac{d U}{d t}=\xi_{1} S-\left(\mu+\gamma_{1}\right) U-\left(\delta_{1}+\omega_{1}\right) U \\
& \frac{d U_{e}}{d t}=\xi_{2} S_{e}+\delta_{1} U-\left(\mu+\gamma_{2}\right) U_{e}-\omega_{2} U_{e} \\
& \frac{d R}{d t}=\omega_{1} U-\left(\delta_{2}+\mu\right) R-\theta R \\
& \frac{d R_{e}}{d t}=\omega_{2} U_{e}+\delta_{2} R-\mu R_{e}
\end{aligned}
$$

dengan

$$
\xi_{1}=\frac{\beta U}{N}+(1-\sigma) \frac{\beta U_{e}}{N}, \quad \xi_{2}=(1-\psi)\left[\frac{\beta U}{N}+(1-\sigma) \frac{\beta U_{e}}{N}\right]
$$

dan

$$
\frac{d N}{d t}=\Lambda-\mu N-\gamma_{1} U-\gamma_{2} U_{e}
$$

dengan

$$
N=S+U+R+S_{e}+U_{e}+R_{e}
$$

Keterangan parameter-parameter yang ada pada persamaan (1) disajikan pada Tabel 1. 
Tabel 1. Keterangan Parameter Model

\begin{tabular}{|c|l|}
\hline Parameter & \multicolumn{1}{|c|}{ Keterangan } \\
\hline$\Lambda$ & Laju rekrutmen populasi rentan. \\
\hline$\varepsilon$ & Bagian dari individu rekruitmen baru dengan edukasi $(0<\varepsilon<1)$. \\
\hline$\rho$ & Laju edukasi terhadap populasi rentan tanpa edukasi. \\
\hline$\omega_{1}\left(\omega_{2}\right)$ & $\begin{array}{l}\text { Laju progresi individu } U \text { berhenti dari pengguna narkoba, } U \text { ke } R\left(U_{e}\right. \\
\left.\text { ke } R_{e}\right)\left(0<\omega_{1}, \omega_{2}<1\right) .\end{array}$ \\
\hline$\delta_{1}\left(\delta_{2}\right)$ & Laju edukasi individu-individu dalam kelas $(R)\left(0<\delta_{1}, \delta_{2}<1\right)$. \\
\hline$\mu$ & Laju kematian secara alami. \\
\hline$\theta$ & $\begin{array}{l}\text { Laju perpindahan populasi yang telah berhenti menggunakan } \\
\text { narkoba kembali menjadi populasi rentan }(0<\theta<1) .\end{array}$ \\
\hline$\gamma_{1}\left(\gamma_{2}\right)$ & $\begin{array}{l}\text { Laju kematian yang disebabkan oleh narkoba pada indivu di kelas } \\
\left(U_{e}\right) \\
\left(0<\gamma_{1}, \gamma_{2}<1\right) .\end{array}$ \\
\hline$\xi_{1}$ & Laju individu populasi $S$ yang berpindah ke populasi $U$. \\
\hline$\xi_{2}$ & Laju individu populasi $S_{e}$ yang berpindah ke populasi $U_{e}$. \\
\hline$\beta$ & $\begin{array}{l}\text { Laju kontak efektif antar individu pengguna dengan individu rentan } \\
(0<\beta<1) .\end{array}$ \\
\hline$\sigma$ & $\begin{array}{l}\text { Faktor reduksi dari penyebaran pengguna narkoba dengan faktor } \\
\text { edukasi }(0<\sigma<1) .\end{array}$ \\
\hline & $\begin{array}{l}\text { Laju efektifitas faktor edukasi dalam mencegah munculnya } \\
\text { pengguna narkoba baru }(0<\psi<1) .\end{array}$ \\
\hline &
\end{tabular}

\subsection{Analisis Kontrol Optimal}

Model dalam sistem persamaan (1) dimodifikasi dengan menerapkan kontrol optimal. Metode yang digunakan untuk menyelesaikan masalah kontrol optimal adalah dengan menggunakan Prinsip Minimum Pontryagin yang dapat dilihat pada (Naidu, 2002). Diberikan variabel kontrol $C=\left\{c \mid c(t)\right.$ terukur dan terbatas, $\left.0 \leq c(t) \leq 1, t \in\left[0, t_{f}\right]\right\}$, di mana $c(t)$ adalah kontrol berupa edukasi. Sehingga diperoleh model penyebaran pengguna narkoba setelah diberikan kontrol pada persamaan (2). 


$$
\begin{aligned}
\frac{d S}{d t} & =(1-\varepsilon) \Lambda+\theta R-\frac{\beta S U+(1-\sigma) \beta S U_{e}}{S+U+R+S_{e}+U_{e}+R_{e}}-\rho(1+c) S-\mu S \\
\frac{d S_{e}}{d t} & =\varepsilon \Lambda+\rho(1+c) S-\frac{(1-\psi) \beta S_{e} U+(1-\sigma)(1-\psi) \beta S_{e} U_{e}}{S+U+R+S_{e}+U_{e}+R_{e}}-\mu S_{e} \\
\frac{d U}{d t} & =\frac{\beta S U+(1-\sigma) \beta S U_{e}}{S+U+R+S_{e}+U_{e}+R_{e}}-\left(\mu+\gamma_{1}\right) U-\delta_{1}(1+c) U-\omega_{1} U \\
\frac{d U_{e}}{d t} & =\frac{(1-\psi) \beta S_{e} U+(1-\sigma)(1-\psi) \beta S_{e} U_{e}}{S+U+R+S_{e}+U_{e}+R_{e}}+\delta_{1}(1+c) U-\left(\mu+\gamma_{2}\right) U_{e}-\omega_{2} U_{e} \\
\frac{d R}{d t} & =\omega_{1} U-\delta_{2}(1+c) R-\mu R-\theta R \\
\frac{d R_{e}}{d t} & =\omega_{2} U_{e}+\delta_{2}(1+c) R-\mu R_{e}
\end{aligned}
$$

Fungsi tujuan dari sistem persamaan (2) adalah sebagai berikut.

$$
F(c)=\min \int_{0}^{t_{f}}\left(S(t)+U(t)+R(t)+\frac{1}{2} K(c(t))^{2}\right) d t
$$

Di mana $t_{f}$ adalah waktu akhir dan $K$ adalah biaya edukasi.

Persamaan Lagrangian dari masalah kontrol optimal yaitu:

$$
L(S, U, R, c)=S(t)+U(t)+R(t)+\frac{1}{2} K(c(t))^{2}
$$

Persamaan Hamilton merupakan penjumlahan antara persamaan (4) dan perkalian fungsi kendala dengan pengali Lagrange. Diberikan pengali Lagrange sebagai berikut.

$$
l^{T}=\left(\begin{array}{llllll}
l_{1} & l_{2} & l_{3} & l_{4} & l_{5} & l_{6}
\end{array}\right)
$$

Sehingga diperoleh persamaan Hamilton sebagai berikut.

$$
\begin{aligned}
& H=S(t)+U(t)+R(t)+\frac{1}{2} K(c(t))^{2}+l_{1}(1-\varepsilon) \Lambda+l_{1} \theta R-l_{1}\left(\frac{\beta S U+(1-\sigma) \beta S U_{e}}{S+U+R+S_{e}+U_{e}+R_{e}}\right) \\
& -l_{1} \rho(1+c) S-l_{1} \mu S+l_{2} \varepsilon \Lambda+l_{2} \rho(1+c) S-l_{2}\left(\frac{(1-\psi) \beta S_{e} U+(1-\sigma)(1-\psi) \beta S_{e} U_{e}}{S+U+R+S_{e}+U_{e}+R_{e}}\right) \\
& -l_{2} \mu S_{e}+l_{3}\left(\frac{\beta S U+(1-\sigma) \beta S U_{e}}{S+U+R+S_{e}+U_{e}+R_{e}}\right)-l_{3}\left(\mu+\gamma_{1}\right) U-l_{3} \delta_{1}(1+c) U-l_{3} \omega_{1} U \\
& +l_{4}\left(\frac{(1-\psi) \beta S_{e} U+(1-\sigma)(1-\psi) \beta S_{e} U_{e}}{S+U+R+S_{e}+U_{e}+R_{e}}\right)+l_{4} \delta_{1}(1+c) U-l_{4}\left(\mu+\gamma_{2}\right) U_{e}-l_{4} \omega_{2} U_{e} \\
& +l_{5} \omega_{1} U-l_{5} \delta_{2}(1+c) R-l_{5} \mu R-l_{5} \theta R+l_{6} \omega_{2} U_{e}+l_{6} \delta_{2}(1+c) R-l_{6} \mu R_{e}
\end{aligned}
$$

Untuk mendapat kondisi yang optimal dari $H$, maka harus dipenuhi syarat stasioner sebagai berikut.

Dengan

$$
\frac{\partial H}{\partial c}=0 \rightarrow c(t)=\frac{\phi}{K}
$$

$$
\phi=l_{1} \rho S-l_{2} \rho S+l_{3} \delta_{1} U-l_{4} \delta_{1} U+l_{5} \delta_{2} R-l_{6} \delta_{2} R
$$


Bersarakan persamaan (6) dan kondisi batas variabel kontrol $0 \leq c(t) \leq 1$, solusi $c(t)$ yang optimal diperoleh sebagai berikut.

Atau dapat ditulis dalam bentuk

$$
c^{*}(t)=\left\{\begin{array}{ccc}
0, & \text { jika } & \frac{\phi}{K} \leq 0 \\
\frac{\phi}{K}, & \text { jika } & 0<\frac{\phi}{K}<b \\
1, & \text { jika } & \frac{\phi}{K} \geq 1
\end{array}\right\}
$$

$$
\boldsymbol{c}^{*}(t)=\min \left\{1, \operatorname{maks}\left[0, \frac{\phi}{K}\right]\right\}
$$

Syarat perlu untuk memperoleh kondisi optimal adalah dengan menyelesaikan persamaan state dan co-state. Persamaan state adalah sebagai berikut.

$$
\begin{aligned}
& \frac{\partial H}{\partial l_{1}}=\dot{S}=(1-\varepsilon) \Lambda+\theta R-\frac{\beta S U+(1-\sigma) \beta S U_{e}}{S+U+R+S_{e}+U_{e}+R_{e}}-\rho(1+c) S-\mu S \\
& \frac{\partial H}{\partial l_{2}}=\dot{S_{e}}=\varepsilon \Lambda+\rho(1+c) S-\frac{(1-\psi) \beta S_{e} U+(1-\sigma)(1-\psi) \beta S_{e} U_{e}}{S+U+R+S_{e}+U_{e}+R_{e}}-\mu S_{e} \\
& \frac{\partial H}{\partial l_{3}}=\dot{U}=\frac{\beta S U+(1-\sigma) \beta S U_{e}}{S+U+R+S_{e}+U_{e}+R_{e}}-\left(\mu+\gamma_{1}\right) U-\delta_{1}(1+c) U-\omega_{1} U \\
& \frac{\partial H}{\partial l_{4}}=\dot{U_{e}}=\frac{(1-\psi) \beta S_{e} U+(1-\sigma)(1-\psi) \beta S_{e} U_{e}}{S+U+R+S_{e}+U_{e}+R_{e}}+\delta_{1}(1+c) U-\left(\mu+\gamma_{2}\right) U_{e}-\omega_{2} U_{e} \\
& \frac{\partial H}{\partial l_{5}}=\dot{R}=\omega_{1} U-\delta_{2}(1+c) R-\mu R-\theta R \\
& \frac{\partial H}{\partial l_{6}}=\dot{R_{e}}=\omega_{2} U_{e}+\delta_{2}(1+c) R-\mu R_{e}
\end{aligned}
$$

Sedangkan persamaan co-state adalah sebagai berikut.

$$
\begin{aligned}
& \frac{\partial H}{\partial S}=-\dot{l}_{1}=-\left(1+l_{1} \Gamma_{A 1}+l_{2} \Gamma_{B 1}+l_{3} \Gamma_{C 1}+l_{4} \Gamma_{D 1}\right) \\
& \frac{\partial H}{\partial S_{e}}=-\dot{l}_{2}=-\left(l_{1} \Gamma_{A 2}+l_{2} \Gamma_{B 2}+l_{3} \Gamma_{C 2}+l_{4} \Gamma_{D 2}\right) \\
& \frac{\partial H}{\partial U}=-\dot{l_{3}}=-\left(1+l_{1} \Gamma_{A 3}+l_{2} \Gamma_{B 3}+l_{3} \Gamma_{C 3}+l_{4} \Gamma_{D 3}+l_{5} \omega_{1}\right) \\
& \frac{\partial H}{\partial U_{e}}=-\dot{l_{4}}=-\left(l_{1} \Gamma_{A 4}+l_{2} \Gamma_{B 4}+l_{3} \Gamma_{C 4}+l_{4} \Gamma_{D 4}+l_{6} \omega_{2}\right) \\
& \frac{\partial H}{\partial R}=-\dot{l}_{5}=-\left(1+l_{1} \Gamma_{A 5}+l_{2} \Gamma_{B 5}+l_{3} \Gamma_{C 2}+l_{4} \Gamma_{D 1}+l_{5} \Gamma_{E 1}+l_{6} \Gamma_{F 1}\right) \\
& \frac{\partial H}{\partial R_{e}}=-\dot{l_{6}}=-\left(l_{1} \Gamma_{A 2}+l_{2} \Gamma_{B 5}+l_{3} \Gamma_{C 2}+l_{4} \Gamma_{D 1}-l_{6} \mu\right)
\end{aligned}
$$

\subsection{Simulasi Numerik}

Sebelum melakukan simulasi, persamaan state dan co-state terlebih dahulu dilakukan diskritisasi dengan menggunakan metode Runge-Kutta orde 4 (Suryanto, 2017). Simulasi numerik diselesaikan dengan menggunakan metode skema maju-mundur Runge-Kutta orde 4. Persamaan state diselesaikan dengan menggunakan skema maju, sedangkan persamaan costate diselesaikan dengan menggunakan skema mundur. Nilai awal yang digunakan adalah 
$S(0)=300, \quad S_{e}(0)=100, \quad U(0)=50, \quad U_{e}(0)=50, \quad R(0)=0$, dan $R_{e}(0)=0$, dan untuk parameter yang digunakan disajikan pada Tabel 2 .

Tabel 2 : Nilai Parameter

\begin{tabular}{|c|c|c|}
\hline Parameter & Nilai & Sumber \\
\hline$\Lambda$ & 10 & Asumsi \\
\hline$\varepsilon$ & 0.40 & Asumsi \\
\hline$\rho$ & 0.10 & (Li dan Ma, 2018) \\
\hline$\mu$ & 0.02 & (Li and Ma, 2018) \\
\hline$\gamma_{1}$ & 0.03 & (Lestari, 2012) \\
\hline$\gamma_{2}$ & 0.02 & Asumsi \\
\hline$\delta_{1}$ & 0.30 & Asumsi \\
\hline$\delta_{2}$ & 0.47 & Asumsi \\
\hline$\omega_{1}$ & 0.40 & Asumsi \\
\hline$\omega_{2}$ & 0.23 & Asumsi \\
\hline$\beta$ & 0.30 & Asumsi \\
\hline$\theta$ & 0.08 & Asumsi \\
\hline$\sigma$ & 0.10 & Asumsi \\
\hline$\psi$ & 0.06 & Asumsi \\
\hline$K$ & 200 & Asumsi \\
\hline & & \\
\hline
\end{tabular}

Hasil simulasi secara numerik dengan melibatkan kontrol dan tanpa melibatkan kontrol ditampilkan pada Gambar 2.

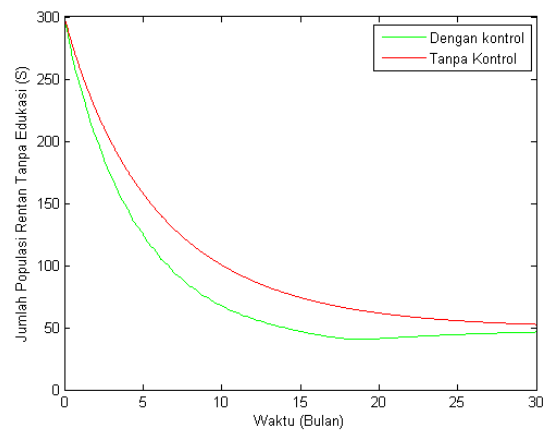

(a)

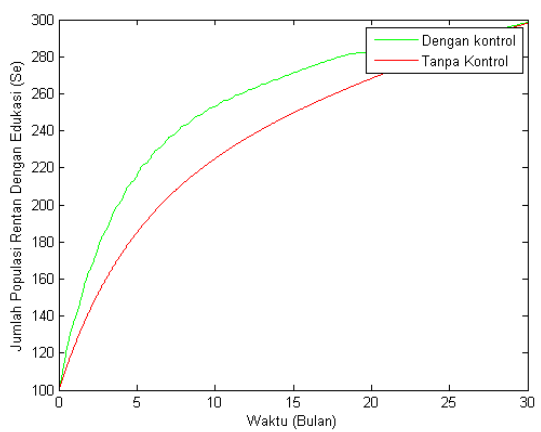

(b) 


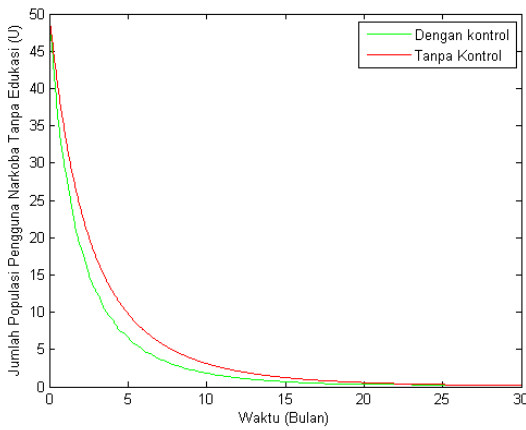

(c)

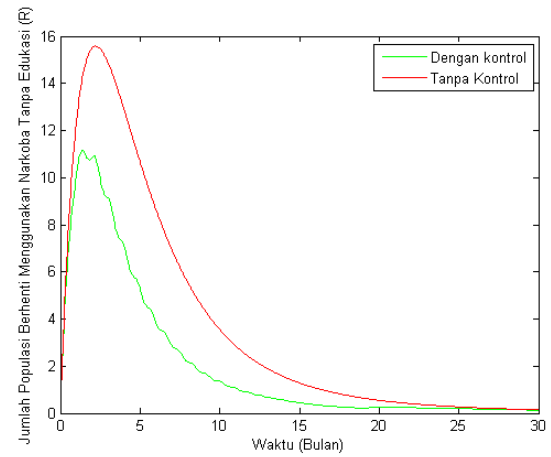

(e)

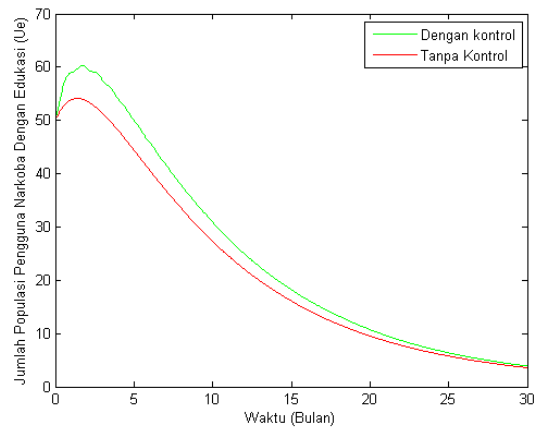

(d)

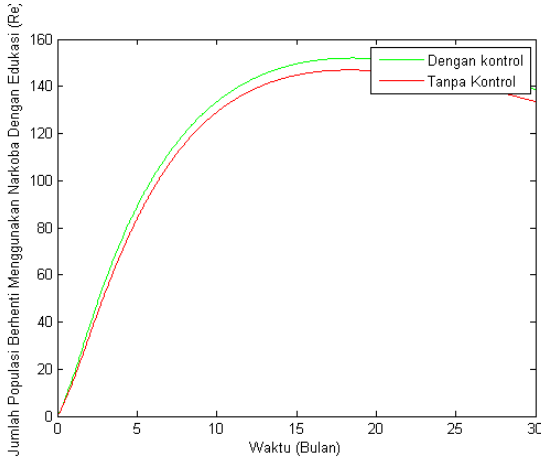

(f)

Gambar 2 : Hasil Simulasi Numerik Dengan dan Tanpa Kontrol

Gambar 2(a) dan 2(b) menunjukkan dinamika populasi rentan menggunakan narkoba tanpa edukasi dan dengan edukasi. Terlihat pada grafik bahwa kedua populasi tersebut memiliki perbedaan saat sebelum diberi kontrol dan setelah diberi kontrol. Gambar 2(a) menunjukkan penurunan populasi rentan tanpa edukasi, namun penurunan populasi tersebut lebih besar penurunannya saat diberi kontrol dari pada sebelum diberi kontrol. Contohnya pada saat $t=14$ jumlah populasi sebelum diberi kontrol sekitar 78 orang, sedangkan setelah diberi kontrol jumlahnya menurun menjadi 50 orang. Gambar 2(b) menunjukkan peningkatan populasi rentan dengan edukasi, namun setelah diberikan kontrol jumlah populasinya mengalami peningkatan lebih besar dari pada sebelum diberi kontrol. Contohnya pada saat $t=10$ jumlah populasi sebelum diberi kontrol sekitar 225 orang, sedangkan setelah diberi kontrol terjadi peningkatan menjadi 253 orang. Hal ini terjadi karena setelah diberi kontrol jumlah populasi rentan menggunakan narkoba tanpa edukasi berkurang dan berpindah ke populasi rentan menggunakan narkoba dengan edukasi.

Gambar 2(c) dan 2(d) menunjukkan dinamika populasi pengguna narkoba tanpa edukasi dan dengan edukasi. Terlihat pada grafik bahwa pemberian kontrol dapat mempengaruhi jumlah populasi pengguna narkoba tanpa edukasi maupun yang diedukasi. Gambar 2(c) menunjukkan bahwa pemberian kontrol pada populasi pengguna narkoba tanpa 
edukasi mengalami penurunan dari pada sebelum diberi kontrol dan lama-kelamaan populasi ini akan menghilang. Contohnya saat $t=5$ jumlah populasi sebelum diberi kontrol sekitar 10 orang, sedangkan setelah diberi kontrol menjadi 7 orang. Begitu juga dengan Gambar 2(d) yang menunjukkan bahwa sebelum dan sesudah diberi kontrol jumlah populasi pengguna narkoba dengan edukasi meningkat kemudian menurun dan lama-kelamaan populasi ini akan menghilang pada saat tertentu. Namun pemberian kontrol pada populasi ini jauh lebih mengalami peningkatan dari pada sebelum diberi kontrol. Contohnya saat $t=2$ jumlah populasi sebelum diberi kontrol sekitar 54 orang dan setelah diberi kontrol jumlahnya meningkat menjadi 60 orang. Hal ini dikarenakan setelah diberi kontrol jumlah populasi pengguna narkoba tanpa edukasi berkurang dan berpindah ke populasi pengguna narkoba dengan edukasi.

Gambar 2(e) dan 2(f) menunjukkan dinamika populasi berhenti menggunakan narkoba tanpa edukasi dan dengan edukasi. Terlihat di grafik bahwa pemberian kontrol sangat berpengaruh pada perubahan jumlah kedua populasi tersebut. Gambar 2(e) menunjukkan bahwa sebelum dan sesudah diberi kontrol jumlah populasi berhenti menggunakan narkoba tanpa edukasi meningkat secara signifikan kemudian menurun, dan dilihat berdasarkan grafik pemberian kontrol pada populasi ini membuat peningkatan dan penurunannya memiliki perbedaan dari pada sebelum diberi kontrol. Contohnya saat $t=5$ jumlah populasi sebelum diberi kontrol sebelum sekitar 11 orang, sedangkan setelah diberi kontrol jumlah populasinya menjadi 5 orang. Penurunan jumlah populasi ini dikarenakan populasinya berpindah ke populasi berhenti menggunakan narkoba dengan edukasi dan berpotensi kembali ke populasi rentan tanpa edukasi. Gambar 2(f) menunjukkan bahwa pemberian kontrol dapat mempengaruhi jumlah populasi berhenti menggunakan narkoba dengan edukasi. Pemberian kontrol pada populasi ini berdampak pada peningkatan jumlah populasinya dari pada sebelum diberi kontrol. Contohnya saat $t=20$ jumlah populasi sebelum diberi kontrol sekitar 147 orang, dan setelah diberi kontrol jumlahnya meningkat menjadi 152 orang. Hal ini terjadi karena setelah diberi kontrol jumlah populasi berhenti menggunakan narkoba tanpa edukasi berkurang dan berpindah ke populasi berhenti menggunakan narkoba dengan edukasi.

\section{KESIMPULAN}

Pemberian kontrol dapat membantu menekan penyebaran pengguna narkona pada populasi baik pada populasi yang diberi edukasi maupun pada populasi tanpa edukasi. Dapat dilihat dari perubahan data populasi sebelum dan setelah diberi edukasi. Setelah penerapan kontrol, terdapat penurunan pengguna aktif narkona dari 10 orang menjadi 7 orang dan terjadi peningkatan populasi yang berhenti menggunakan narkoba dari 84 orang menjadi 89 orang. 


\section{DAFTAR PUSTAKA}

[1] BNN, Penggunaan Narkotika di Kalangan Remaja Meningkat, https://bnn.go.id/penggunaannarkotika-kalangan-remaja-meningkat/, 2019, (diakses pada 20 Desember 2019).

[2] Engelhart, M., Lebiedz, D. dan Sager, S., Optimal Kontrol For Selected Cancer Chemotherapy ODE Models: A View On The Potential Of Optimal Schedules And Choice Of Objective Function, Mathematical Biosciences 229(1), 2011, 123-134.

[3] Hota, S., Agusto, F., Joshi, H.R., dkk., Optimal Kontrol And Stability Analysis Of An Epidemic Model With Education Campaign And Treatment, American Institute of Mathematical Sciences (AIMS), 2015, 621-634.

[4] Husain, M. R., Nurwan dan Resmawan, Analisis Kestabilan Model Penyebaran Pengguna Narkoba Dengan Faktor Edukasi, BAREKENG: Jurnal IImu Matematika dan Terapan 14(1), 2020, 69-78.

[5] Lestari, Pengembangan Model Penyebaran Pengguna Narkoba White-Comiskey, Bogor, 2012, Institut Pertanian Bogor.

[6] Li, J. dan Ma, M., The analysis of a drug transmission model with family education and public health education, Infectious Disease Modelling 3, 2018, 74-84.

[7] Mulone, G. dan Straughan, B., A note on heroin epidemics, Mathematical Biosciences 218(2), 2009, 138-141.

[8] Naidu, D., Optimal Kontrol Systems, New York, 2002, CRC Press.

[9] Nebi, O., Faktor Penyebab Pengguna Narkotika di Kalangan Masyarakat, Wajah Hukum 3(1), 2019, 81-88.

[10] Oke, S. I., Matadi, M. dan Xulu, S., Optimal Kontrol Analysis of a Mathematical Model for Breast Cancer, Mathematical and Computational Applications 23(2), 2018, 21.

[11] Suryanto, A., Metode Numerik Untuk Persamaan Diferensial Biasa dan Aplikasinya dengan Matlab, Malang, 2017, Universitas Negeri Malang.

[12] Undang-Undang Republik Indonesia Nomor 35 Tahun 2009 Tentang Narkotika. 12 Oktober 2009. Lembaran Negara Republik Indonesia Tahun 2009 Nomor 143. Jakarta.

[13] Wang, X., Yang, J. dan Li, X., Dynamics of a Heroin Epidemic Model with Very Population, Applied Mathematics 02(06), 2011, 732-738.

[14] White, E. dan Comiskey, C., Heroin epidemics, treatment and ODE modelling, Mathematical Biosciences 208(1), 2007, 312-324.

[15] Wijayanti, D., Revolusi Mental: Stop Penyalahgunaan Narkoba, Yogyakarta, 2016, Indoliterasi. 